\title{
Changbai Mountain Natural Resources Reserve based on ecological footprint theory ecological structure optimization
}

\author{
Qiufei Wang ${ }^{1}$, Shuhan Zhang $^{1}$, Bingjie Tang ${ }^{1}$ \\ ${ }^{1}$ Department of Shenyang Jianzhu University, 110168, Shenyang, LN, China
}

\begin{abstract}
Taking the Changbai Mountain Natural Resources Protection Area as the research object, combined with the ecological footprint theory, using the quantitative analysis method to calculate the ecological footprint of Changbai Mountain Natural Resources Protection Area, it is found that the Changbai Mountain Natural Resources Protection Area is in an ecological deficit state. The rational layout infrastructure, the optimization of scenic area management mode and the gradual realization of collaborative management optimization methods are proposed, which provide reference and reference for the follow-up development of Changbai Mountain Natural Resources Protection Area.
\end{abstract}

\section{Research status at domestic and abroad}

With rapid development and certain characteristics has been selected as the research object. The ecological footprint theory of Changbai Mountain is analyzed by using ecological footprint theory and other methods to find out existing problems and put forward practical problems.

Professor Willian E. Rees [1] first proposed the ecological footprint theory, and then his student Wackemagel applied the ecological footprint theory to the ecological footprint analysis of international tourism for the first time, and used this theory to calculate the ecological footprint of Venice with Yount etc. ${ }^{[2]}$ It also analyzes the relationship between ecological footprint and tourism activities.

Although the introduction of tourism ecological footprint theory in China is relatively late, many scholars have applied it to different fields and analyzed ecological problems. For the first time, Xi Jianchao ${ }^{[3]}$ combined the ecological footprint theory with the tourism field. Through the analysis of the proportion of different ecological resources occupied by different tourism consumption behaviors, the ecological occupancy measurement model was proposed. Zhang Jinhe etc. ${ }^{[4]}$ classified the land in a simple way and divided it into six parts: built-up land, forest land, grassland, cultivated land, water area and fossil energy land. At the same time, the tourism ecological footprint is divided into six parts: accommodation, transportation, catering, entertainment, shopping and sightseeing, and this method is applied to calculate the ecological footprint of Huangshan City Tourist Area. It provides a reference for the selection of indicators for the subsequent research. Kang Wenxing etc. ${ }^{[5]}$ divided the tourism ecological footprint into a transferable ecological footprint, which indicates that the tourism area can transfer its ecological pressure to other areas in a certain way, and the non-transferable ecological footprint, reflecting the need for the tourism area to bear. Ecological pressure, and based on this calculation of the tourism ecological footprint of Zhangjiajie in 2006.

Foreign scholars have done a good job in the function and classification of tourism facilities, site selection of tourism facilities and material design. In 2003, Albert H. Goode $^{[6]}$ presented the design and practices of tourist facilities in national parks in the form of "National Park Recreation Design” and Leonard E. Phillips' Park Design and Management in 2003 .Manuel Baud-Bolafred Lawson $^{[7]}$ gave a detailed introduction to the classification and design methods of tourism facilities in the "Travel and Recreation Planning and Design Manual", while emphasizing the relationship between development and protection. The relationship is that facilities in the relatively fragile environment should not be too scattered, and should be concentrated in a certain section to maintain the rationality of the ecological environment capacity of the area, and fundamentally ensure the ecological nature of the tourism facilities.

At present, although the basic framework for the study of ecological footprint theory has been formed, there are few applied studies on ecological compensation in specific areas. The author refines the ecological compensation mechanism that has been applied to a wide range in the past, and studies the compensation mechanism for a certain region to make it more practical and applicable, so as to meet the needs of ecological 
optimization in specific regions. The author takes the Changbai Mountain Natural Resources Protection Area with rapid development of tourism in recent years as the research object, and uses the ecological footprint theory to analyze the ecological status of Changbai Mountain Natural Resources Protection Area, find out the existing problems and propose improvement plans for the problems.

\section{Introduction to Changbai Mountain Natural Resources Reserve}

\subsection{Natural conditions of Changbai Mountain Natural Resources Reserve}

Jilin changbai mountain natural resources reserve is located in the southeast of Jilin Province, bordering Antu County of Yanbian Korean Autonomous Prefecture, Fusong County of Baishan City and Changbai Korean Autonomous County, adjacent to the southeastern part of the Democratic People's Republic of Korea. The maximum length of the entire tourist area is 80 kilometers, the maximum width of east and west is 42 kilometers, the total area is 196465 hectares, and the total forest volume is 43.735 million cubic meters. Changbai Mountain belongs to the volcanic landform. There are more than 200 volcanoes of different sizes in the area. The most typical one is the main landscape of the park: the largest giant volcano in China, Changbai Mountain Volcano, is the main peak of Changbai Mountain. There are a variety of geological and geomorphic landscapes formed by internal and external geological processes such as flowing water and glaciers. The plants in the area belong to the Changbai Mountain flora, the ecosystem is relatively complete, and the plant resources are abundant. The river network in the Changbai Mountain Natural Resources Reserve is densely distributed, and the rivers and rivers are large and horizontal, mainly based on the Songhua River system.

\subsection{Economic and tourism development status of Changbai Mountain Natural Resources Reserve}

Tourism development status of Changbai Mountain Natural Resources Reserve: In 2018, the Changbai Mountain Natural Resources Reserve achieved rapid and steady development. The number of tourists at home and abroad was $2,700,300$, an increase of $12.8 \%$ over the previous year; the total tourism revenue was 2.565 billion yuan, an increase of $16.52 \%$. The number of tourists in Changbai Mountain Scenic Area was 1.934 million, an increase of $22.92 \%$; the tourism income of scenic spots was 530 million yuan, an increase of $17 \%$. In 2016, there were 21 tourism construction projects in Changbai Mountain Natural Resources Reserve with a total investment of 11.3 billion yuan. Among them, there are 12 projects under construction, with a total investment of
6.405 billion yuan and 9 new projects with a total investment of 4.675 billion yuan.

The Changbai Mountain Scenic Area is rich in tourism resources, including magnificent and magical volcanic landscapes; complete mountain forest ecosystem; unique snow and ice scenery in the north; numerous waterfall lakes and volcanic mineral springs; and unique folk customs. The scenic area currently has a total of 18 scenic spots including Tianchi, Changbai Mountain Waterfall, Changbai Mountain Grand Canyon and Alpine Garden. The combination of various attractions is good, and the scenery of the mountains and rivers is full of interest. In addition, Changbai Mountain Tourism Zone has developed a number of facilities around the six aspects of "eat, travel, live, entertain, purchase and travel" , including: snow parks, theme parks, ski resorts, etc., to meet the tourist needs of all types of tourists.

\section{Establishment of ecological profit and loss model of Changbai Mountain Natural Resources Reserve}

\subsection{Indicator selection}

The construction of tourism ecological profit and loss model should be based on tourism activities or behavior as indicators. The author follows the principles of accessibility, pertinence and completeness, and selects six indicators among a large number of tourism ecological footprint indicators, including five kinds of behaviors and one major pollution that occur frequently during the tourism process, namely transportation, catering, accommodation, Shopping, entertainment and solid waste. And through the calculation of six indicators, the ecological footprint of Changbai Mountain Natural Resources Reserve Tourists is obtained.

\subsection{Data source}

The data needed to calculate the tourist's ecological footprint and environmental ecological carrying capacity are divided into three categories: 1. Basic data. It includes the total amount, composition, area and utilization rate of tourism transportation, accommodation, catering, shopping and entertainment facilities, the quantity and type of food and energy consumed by local residents, the number of tourists and their energy consumption, and various biological productions, as well as the annual productivity level of Biological productive land. The data used by the author comes from the Changbai Mountain Management Committee and the 2018 Changbai Mountain Conservation Development Zone Yearbook and Gazette.2. Survey data. Including tourist transportation choices, travel distance, etc., the relevant data is derived from the analysis results of the questionnaire.3. Other data. Including the average energy consumption of different types of vehicle units, the average calorific value of fossil fuel per unit area, etc., 
data are from the international standard data sheet.

\subsection{Quantitative analysis of ecological footprint of Changbai Mountain Natural Resources Reserve}

Calculate the selected six indicators one by one, and the calculation formula is

$$
E F=E F_{\mathrm{T}}+E F_{\mathrm{H}}+E F_{\mathrm{R}}+E F_{\mathrm{M}}+E F_{\mathrm{E}}+E F_{\mathrm{W}}
$$

In the formula: $E F$ is the ecological footprint of tourism; $E F_{\mathrm{T}}$ is the ecological footprint of tourism transportation; $E F_{\mathrm{H}}$ is the ecological footprint for tourism accommodation; $E F_{\mathrm{R}}$ is the ecological footprint for tourism and catering; $E F_{\mathrm{M}}$ is the ecological footprint for tourism and shopping; $E F_{\mathrm{w}}$ is the ecological footprint for tourism and entertainment; and $E F_{\mathrm{w}}$ is the ecological footprint of tourism solid waste.

(1) The ecological footprint of tourism transportation is mainly calculated in two parts: the built-up area of transportation facilities (including railway stations, bus stations, airports, etc.) and the energy consumption required for tourists to travel from the starting point to the tourist area and the tourist area (e.g. Tourist cars in Changbai Mountain Scenic Area, etc.). The calculation formula is

$$
E F_{\mathrm{T}}=\alpha_{1} \sum\left(A_{\mathrm{i}} \times B_{\mathrm{i}}\right)+\alpha_{2} \sum\left(N_{\mathrm{i}} \times C_{\mathrm{i}} \times D_{\mathrm{i}}\right)
$$

In the formula: $\alpha_{1}$ is the equilibrium factor for the built-up; $\alpha_{2}$ is the fossil energy balance factor; $A_{i}$ is the area occupied by the transportation facilities; $B_{\mathrm{i}}$ is the frequency of use of the traffic facilities; $N_{\mathrm{i}}$ is the number of passengers in the transportation facilities; $C_{\mathrm{i}}$ is the per capita ecological footprint of the vehicle; $D_{\mathrm{i}}$ is average distance traveled by tourists. Tourists to Changbai Mountain usually use four kinds of vehicles, such as airplanes, trains, long-distance buses and cars. For the convenience of calculation, the four types of vehicles are classified into three categories, namely, airplanes, railways and highways. According to statistics, tourists from Changbai Mountain mainly come from Guangdong, Beijing and Jilin. Therefore, the average distance of tourists from these three types of vehicles is estimated to be $4749 \mathrm{~km}, 1770 \mathrm{~km}$ and $567 \mathrm{~km}$. The traffic facilities in the Changbai Mountain Scenic Area are mainly scenic buses, which can be classified as road traffic, and the viewing distance of the scenic spots in the scenic area is about $140 \mathrm{~km}$. According to the relevant literature, the per capita ecological footprint of these three types of vehicles is $0.38 \mathrm{hm} 2, \quad 0.174 \mathrm{hm} 2$ and $0.31 \mathrm{hm} 2$, respectively.

(2) The ecological footprint of tourism accommodation mainly calculates two parts: the first is the area of the built-up area provided by the accommodation facilities for tourists; the other is the energy consumed by the hotel, such as lighting, air-conditioning, washing and other services provided during the stay of tourists. . Among them, the energy consumption of accommodation facilities is mainly gas. The calculation formula is

$$
E F_{\mathrm{H}}=\alpha_{1} \sum\left(E_{\mathrm{i}} \times F_{\mathrm{i}}\right)+a_{2} \sum\left(365 \times E_{\mathrm{i}} \times g \times H_{\mathrm{i}} / r\right)
$$

In the formula: $E_{\mathrm{i}}$ is the number of beds provided for accommodation facilities; $F_{\mathrm{i}}$ is the area occupied by each bed; $g$ is the average annual usage rate of the rooms in the tourist area; $H_{\mathrm{i}}$ is the energy consumed for each bed; $r$ is the average calorific value of fossil fuels in the world According to comprehensive statistics and survey results, there are 25 star-rated hotels and star-rated hotels in Changbai Mountain Natural Resources Reserve, with 7767 beds and 322 family hotels with 8800 beds. The annual room occupancy rate is approximately $60 \%$. The level and scale of these accommodation facilities are different. The built-up area of the bed and the energy consumption are not the same. Considering the relevant literature and the number of rooms in various accommodation facilities, the accommodation facilities of each bed in the Changbai Mountain area can be built. The area is set at $1000 \mathrm{~m} 2$ and the energy consumption is $80 \mathrm{MJ}$.

(3) The ecological footprint of tourism and catering is mainly calculated in three parts: the required area for the establishment of catering facilities, the fossil energy area for providing energy for catering services, and the productive land area corresponding to the consumption and consumption of tourists. As some hotels in the Changbai Mountain Natural Resources Reserve provide accommodation services, they also provide catering services. In order to avoid double counting, the resources for catering in the accommodation are also integrated into the ecological footprint of the accommodation, and no calculation is made here. The calculation formula is

$$
E T_{\mathrm{R}}=\alpha_{1} \sum S_{\mathrm{i}}+\alpha_{2} \sum\left(N \times I \times k_{\mathrm{i}} / r\right)+\alpha_{3 \mathrm{i}} \sum\left(N \times I \times J_{\mathrm{i}} / p_{\mathrm{i}}\right)
$$

In the formula: $\alpha_{3 \mathrm{i}}$ is the bio-productive land balance factor; $S_{\mathrm{i}}$ is the area occupied by the catering facilities; $N$ is the number of visits; $I$ is the average number of days visited; $k_{\mathrm{i}}$ is the daily consumption of energy per capita; $J_{\mathrm{i}}$ is the daily consumption of food per capita; $p_{\mathrm{i}}$ is the productivity corresponding to consumption of food Average annual productivity of land. According to statistics, there are 1,100 catering shops in Changbai Mountain Natural Resources Reserve, including various restaurants, restaurants, drinks shops, etc. The average area of shops is $80 \mathrm{~m} 2$.

(4) The tourism shopping ecological footprint mainly calculates two parts, including the shopping area of shopping malls, convenience stores, tourist souvenir shops, etc.; the energy consumed by the production of goods for sale accounts for the productive land area. Since most visitors to the Changbai Mountain Natural Resources Reserve will purchase ginseng and rarely purchase other products, only ginseng is calculated when calculating the energy consumption of the product, and 
other products are ignored. The calculation formula is

$$
E F_{\mathrm{M}}=\alpha_{1} \sum U_{\mathrm{i}}+\alpha_{2} \sum\left(\left(L_{\mathrm{i}} / M_{\mathrm{i}}\right) \div O_{\mathrm{i}}\right)
$$

In the formula: $U_{\mathrm{i}}$ is the area occupied by the shopping facilities; $L_{\mathrm{i}}$ is the consumption expenditure of the goods purchased by the tourists; $M_{\mathrm{i}}$ is the average selling price of the goods; $O_{\mathrm{i}}$ is the annual average productivity of the productive land corresponding to the consuming goods. According to statistics, the construction area of the shopping facilities in Changbai Mountain Natural Resources Reserve is about $110 \mathrm{hm} 2$. The total tourism revenue of the Changbai Mountain Natural Resources Reserve in 2016 is 25.65 yuan, of which $28 \%$ are tourism goods and 259.25 yuan per capita tourism goods. The Changbai Mountain Natural Resources Reserve has many special products, but the Changbai Mountain ginseng has a high reputation. It is assumed that the tourists' consumption expenditures are all used to purchase ginseng, and the average price of Changbai Mountain ginseng is 600 yuan $/ \mathrm{kg}$, and the per capita purchase amount is $0.43 \mathrm{~kg}$. According to statistics, the annual productivity of ginseng in Changbai Mountain is $450 \mathrm{~kg} / \mathrm{hm} 2$.

(5) Tourism and recreation are as follows. Ecological footprint is mainly calculated in two parts: one is the area where the entertainment facilities are built and the energy consumed, such as theme parks and ski resorts; the other is the area of the plank road and the viewing space in the scenic area. The calculation formula is

$$
E F_{\mathrm{E}}=\alpha_{1}\left(\sum Q_{\mathrm{i}}+\sum T_{\mathrm{i}}\right)
$$

In the formula: $Q_{\mathrm{i}}$ is the area of the recreation and entertainment facilities; $T_{\mathrm{i}}$ indicates: the roads and viewing areas for the natural resources conservation area. In addition to its attractions, Changbai Mountain Natural Resources Reserve has a variety of leisure and entertainment venues, including 15 theme leisure plazas including Meirensong Square, with a total area of approximately 230,242 $\mathrm{m} 2$; and 6 scenic bridges including Wangyun Bridge, with a total area of approximately 1898.7. M2. Changbai Mountain Wanda Ski Resort has 6 ski resorts with a total area of about $3000 \mathrm{hm}$; 9 hot springs including Lanjing Hot Spring, with a total area of $225,000 \mathrm{~m} 2$; and Lushuihe International Hunting Ground, covering an area of $30,800 \mathrm{hm}$. The viewing space in the Changbai Mountain Scenic Area is the extension of the plank road. Therefore, only the area of the plank road in the scenic area can be calculated. The total area of the plank road is about $39,930 \mathrm{~m} 2$.

(6) Sixth is ecological footprint of tourism solid waste. As long as tourists visit the scenic spot, they will inevitably produce a certain amount of pollutants. If not treated properly, the solid waste generated will cause damage to the scenic environment. Most of the tourists who travel to Changbai Mountain have accommodation needs, and the ecological footprint of tourism solid waste should be considered when calculating the tourism ecological footprint. At present, the Changbai Mountain Natural Resources Reserve uses mainly sanitary landfill methods to treat solid waste generated by tourists.
Therefore, the following factors should be considered in the calculation: First, the land area required for landfill waste, and land for landfill waste. It is mainly based on cultivated land; the second is to absorb the forest land required for tourists to produce $\mathrm{CO} 2$. The calculation formula is

$$
E F_{\mathrm{w}}=\alpha_{1} \times S+\alpha_{2} q^{D O C} \times W \times Q / P a
$$

In the formula: $S$ is the area of cultivated land used for waste disposal; $q^{D O C}$ is the proportion of organic carbon contained in the unit waste; $W$ is the $\mathrm{CO} 2$ equivalent coefficient of organic carbon; $Q_{\text {is the amount of waste }}$ generated; $\mathrm{Pa}$ is the average amount of $\mathrm{CO} 2$ absorbed per 10,000 square meters of forest land.

\subsection{Calculation of ecological carrying capacity of Changbai Mountain Natural Resources Reserve}

In order to understand the sustainable development degree of Changbai Mountain Natural Resources Conservation Area more intuitively, the author introduces the ecological capacity model to quantify it. The calculation formula is

$$
E C=N e c=N \times \sum(a j \times y j \times r j)
$$

In the formula: $E C$ is the ecological carrying capacity, $N$ is the population, $e c$ is the per capita ecological carrying capacity, $a_{\mathrm{j}}$ is the per capita bio-productive land area, $y_{\mathrm{j}}$ is the yield factor, and $r_{\mathrm{j}}$ is the equilibrium factor.

The author calculates the ecological carrying capacity of the Changbai Mountain Natural Resources Reserve by using the types of land occupied by tourist attractions and tourist facilities in the Changbai Mountain Natural Resources Reserve.

\section{Analysis of the current situation of ecological environment in Changbai Mountain Natural Resources Reserve}

\subsection{Ecological status of Changbai Mountain Natural Resources Reserve}

Ecological profit and loss is an important indicator for the sustainable development of regional tourism. The calculation formula is

$$
E D=E C-E F
$$

In the formula: $E C$ for ecological carrying capacity, $E F$ for the ecological footprint. At that time, $E C \geq E F$ it was called an ecological surplus, and when it was $E C<E F$, it was called an ecological deficit.

By comparing the tourism ecological footprint and the tourism ecological carrying capacity, it is found that the ecological footprint of Changbai Mountain Natural 
Resources Protection Area is greater than the demand, showing an ecological deficit state, the total ecological deficit is 23466.12544 gha, and the per capita ecological deficit is $87.7096610-4$ gha.

\subsection{Analysis of Tourism Ecological Footprint Structure of Changbai Mountain Natural Resources Reserve}

By analyzing the ecological footprint of Changbai Mountain Natural Resources Reserve (see Figure 1), it is found that the tourism and recreation ecological footprint ranks first with $74.23 \%$, indicating that Changbai Mountain Natural Resources Reserve has more facilities for entertainment and entertainment. Changbai Mountain Natural Resources Reserve has unique natural resources, and local snacks and accommodations also attract many tourists. Therefore, Changbai Mountain Natural Resources Reserve has more catering and accommodation facilities, accounting for $15.80 \%$ and $6.55 \%$ respectively. It shows that the Changbai Mountain Natural Resources Reserve focuses on the development of tourism, and has built many tourist and entertainment facilities, catering facilities and accommodation facilities, which consume a lot of natural resources. As the tourism and recreation ecological footprint accounts for the largest proportion, to reduce the ecological environment pressure of the tourist area and reduce the ecological footprint of tourism and entertainment, we can start from slowing down the construction of recreational facilities and rationally controlling the number and scale of tourists. However, with the economic development and tourism boom, the number of tourists visiting the Changbai Mountain Natural Resources Reserve will gradually increase, and the Changbai Mountain Natural Resources Reserve will continue to build related tourism facilities, and the ecological footprint will further increase.

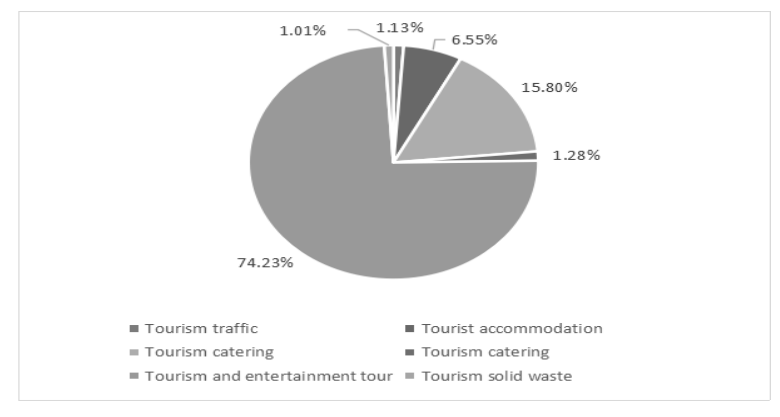

Fig. 1. Composition of the ecological footprint of Changbai Mountain Natural Resources Reserve

\subsection{Analysis of land types of tourism ecological footprint in Changbai Mountain Natural Resources Reserve}

Among the four types of bio-productive land (see Figure 2 ), the proportion of completed land is the largest, accounting for $81.57 \%$, grassland accounting for $13.18 \%$, and fossil energy land accounting for $3.66 \%$. The built-up site plays a decisive role in the size of the tourism ecological footprint. Therefore, in order to reduce the ecological deficit of the Changbai Mountain Natural Resources Reserve and reduce the tourist ecological footprint, it is necessary to start from the largest proportion of the completed land and gradually reduce the area of the built land. With the continuous development of the tourism economy, the number of tourists receiving the Changbai Mountain Natural Resources Reserve will inevitably increase, and the demand and consumption of energy will increase accordingly. Therefore, the area of the newly built land will be reduced to the Changbai Mountain Natural Resources Reserve. Sustainable development is essential.

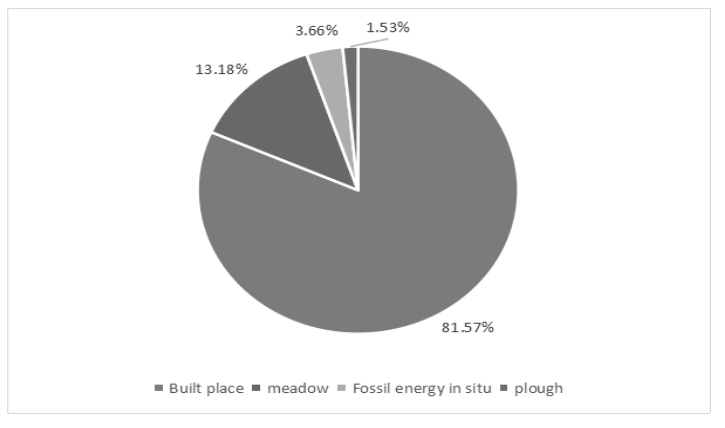

Fig. 2. The composition of the ecological footprint of the Changbai Mountain Natural Resources Reserve

\subsection{Problems in infrastructure construction of Changbai Mountain Natural Resources Reserve}

(1) The energy consumption of tourism and catering infrastructure is excessive. As can be seen from Figure 1, tourists consume a large proportion of food and energy, in addition to the high demand for food energy from Changbai Mountain Natural Resources Reserve, on the other hand, the catering department of Changbai Mountain Natural Resources Reserve is meeting the basic diet of tourists. On the basis of demand, in order to attract more tourists, an additional food stall with local characteristics is set up, occupying a large amount of ecological land. Some food stalls also have a certain degree of damage to the ecological environment. For example, the well-known snacks in Changbai Mountain,

"hot spring boiled eggs", soaked a large number of eggs in the hot spring pool, causing pollution to the water quality.

(2) The layout of tourism accommodation infrastructure is unreasonable. The construction of tourist accommodation facilities is the most concerned factor for tourists. As can be seen from Figure 1, the residential infrastructure of Changbai Mountain Natural Resources Reserve has a large area of construction and occupies a large amount of productive land, reflecting the unreasonable layout of its accommodation facilities problem. At the same time, the Changbai Mountain Natural Resources Reserve protects tourists and builds 
'cabins' with local characteristics for tourists to live in. This practice consumes too much local forest resources and has potential safety hazards. Cause more damage. The main purpose of the accommodation facilities in the tourist area is to assist the tourists to visit more comfortably and conveniently, and should not be a "touring facility" to attract tourists. At the same time, accommodation facilities are not energy-saving and environmentally friendly in terms of heating methods. Changbai Mountain has a low temperature in winter, and indoor heating is mainly used. It consumes a lot of fossil energy and causes a certain degree of environmental pollution.

(3) Tourism transportation infrastructure consumes too much energy and is seriously polluted. The Changbai Mountain tourism transportation infrastructure is divided into two parts: external transportation and internal transportation. There are three main types of external traffic: tourist buses on the highway, high-speed rail and motor trains in the railway, and airplanes. The ecological footprint of these three ways is not much, indicating that the area of external traffic is within a reasonable range. The main problem lies in internal traffic. There are two main types of internal traffic: one is the sightseeing bus in the scenic area, and the other is the special off-road vehicle used in Tianchi. These internal transportation methods generate a large amount of exhaust pollution while destroying fossil energy polluting the natural environment of the scenic spot.

(4) Various stakeholders in Changbai Mountain Natural Resources Reserve lack awareness of ecological collaborative management.The construction of ecotourism facilities emphasizes the role of ecological balance, the optimization and regulation of ecological network patterns, the function of ecological functions and the development of ecological benefits. However, regardless of the government, tourism companies and tourists, the sense of balance needs to be strengthened. Tourists only care about tourism pleasure, but they do not pay attention to tourism while protecting the environment. Tourism companies also pursue economic benefits and ignore excessive development destruction. The government has not proposed relevant laws and regulations to promote the tourism environment and economic balance and sustainable development.

\section{Ecological structure optimization of Changbai Mountain Natural Resources Reserve}

\subsection{Rational layout of infrastructure}

(1) Tourism accommodation facilities. Since a large number of accommodation facilities have been built and put into use, considering the long-term development of the scenic spot, the completed facilities will be reconstructed within a reasonable construction area, for example, replacing more environmentally friendly heating fuels and controlling exhaust emissions. At the same time, the safety of the tourists who choose to live in the "chalet" is prohibited, and it is forbidden to use flammable substances such as smoke and fire to ensure the safety of the scenic spot.

(2) Tourism and catering facilities. The decentralized food and beverage areas will be integrated and centralized management will be carried out. Only the fast food sales points such as selling drinks and not requiring processing will be reserved in the scenic area. According to the situation of the scenic spot, it is reasonably divided and strictly controlled. For example, a sales point is set every $1000 \mathrm{~m}$. For areas that are centrally managed, reduce the number of merchants selling similar foods, and gradually reduce the area of tourism and catering.

(3) Tourism transportation facilities. Strengthen cooperation with transportation facilities around the scenic spot to reduce obstacles to the development of scenic spots. At the same time, it is reasonable to plan the route that needs to travel by car in the scenic spot, reduce unnecessary energy consumption caused by detours, and change the sightseeing vehicles in the scenic spot into more environmentally friendly battery vehicles in batches to reduce exhaust emissions.

\subsection{Optimize the scenic area management mode}

(1) Integrate surrounding tourism resources. The tourist focus of most tourists is concentrated in the main scenic spot of Changbai Mountain. From the perspective of the distribution of scenic spots, it is still a form of "point" Therefore, it is necessary to deepen the development strategy of surrounding tourism, gradually form a basic "serial line", connect the surrounding scenic spots with the main scenic spot, expand the range of tourists to visit, reduce the bearing pressure of the main scenic spot, integrate ecological tourism resources, and realize the tourism area' s balanced and sustainable development.

(2) Diversification of tourism projects. One of the characteristics of Changbai Mountain tourism is that the tourism season is very obvious. The number of tourists in different seasons is very different, which not only seriously affects the ecological protection of the scenic spot, but also is not conducive to maintaining stable economic benefits. Therefore, it is possible to appropriately increase the exhibitions and lectures on the natural environment and historical development of Changbai Mountain, interact with local people, and experience local life, etc., to reasonably disperse the number of tourists and reduce the ecological pressure of the scenic spots. In addition, it is also possible to set up excursions in the scenic spot according to the different needs of tourists of different ages, such as entertainment facilities for children to play, leisure facilities for the elderly to relax, etc., and the tourists are reasonably dispersed from the inside of the scenic spot.

(3) Improve the management system of the tourist area. Since the establishment of the Changbai Mountain Management Committee, the scope of management has also been constantly changing, and the problem of ambiguous powers and responsibilities has often arisen. Therefore, the Changbai Mountain Management 
Committee should conduct close cooperation and interaction with the surrounding districts and counties, conduct regular investigation visits, clarify the responsible departments of the areas where the jurisdiction changes, reduce the problem of mismanagement caused by unclear powers and responsibilities, and adapt to the timely updating of the management system as well as the changing economic environment of Changbai Mountain Natural Resources Reserve.

\subsection{Gradually realize collaborative management}

(1) Collaboration between tourism companies. The synergy between enterprises is the basis for the coordinated development of ecotourism in Changbai Mountain Natural Resources Reserve. Tourism enterprises involve many fields such as catering, residence, transportation, shopping, and travel agency. Therefore, tourism enterprises should start from these five important areas in the construction of ecotourism infrastructure. It is necessary to raise awareness of ecotourism among other industry entities, strengthen the service and guidance of tourism enterprises to other enterprises, and promote the integration of tourism with other enterprises. Pay attention to the appropriateness of resource development, and pay attention to environmental friendliness when producing, selling and consuming tourism products.

(2) The synergy of tourism industry clusters, that is, the cooperation between relevant partners and government departments in the tourism industry chain. On the one hand, we will strengthen the government's understanding of the development of eco-tourism and eco-tourism infrastructure construction management, and issue relevant policies in a targeted manner. Through the implementation of policies, the awareness of ecological environment protection of managers and tourists will be enhanced from the root cause. On the other hand, we need to strengthen the unified coordination of ecological planning. Tourism enterprises must first conduct in-depth study on policies, and then use them according to the needs of tourism areas and existing policies to achieve collaborative management between the tourism industry and the government.

\section{The conclusion and prospect}

Through reading and sorting out a large number of documents, this paper finds the entry point of the thesis problem. Based on the ecological footprint theory, sustainable development theory and collaborative management theory, it analyzes the ecological status of the Changbai Mountain Natural Resources Reserve and the status quo of infrastructure construction management. Through a large amount of literature, statistical yearbooks and survey data to describe the sustainable development of tourism in Changbai Mountain Natural Resources Reserve and the study of ecological footprint model, it finds that the tourism ecological deficit in Changbai Mountain Natural Resources Reserve is serious.
Aiming at the obstacles and problems in the coordinated development of Changbai Mountain Natural Resources Reserve, this paper proposes relevant development strategies and ways to achieve it.

The issue of sustainable tourism development and collaborative management of tourism infrastructure is a relatively complex issue involving a wide range of content. Due to the author's own research ability and the level of knowledge, this paper's exploration of the research on the cooperative management of infrastructure in Changbai Mountain tourism area is relatively superficial, and there are still many shortcomings, such as the need to further deepen in the theoretical point of view. Some conclusions are still certain, and research methods and methods need to be further deepened and innovated. There are still many areas that require further research

*Phase results of the Humanities and Social Sciences Project of the Ministry of Education

Item Number: 18YJC790167

\section{References}

1. M.Wackernagel, C.Monfreda, K.Heinz Erb, H.Haberl,E.F.,L.U.Policy,21(2003).

2. V.Zyl. T.M.,Tourism Economics, 18,43-57(2012)

3. X.Jianchao,G.Quansheng, C.Shengkui,A. P.S.J.P.N.R.,2224-229,(2004)

4. Z.Jinhe,Z.Jie.Tour.Eco.Foot.,ActaGeo.Sinica,5,763771,(2004)

5. Yan.Kang,W.xing.Impr..eco.footp.,Acta Eco. Sini.,11,5401-5409,(2008)

6. A.H. Good,National Park Recreation Design, C.B. I.Press, (2003)

7. M.B.Lawson,T.Ziying,W.Bihu,Tour.Rec.Pla.Handb ook,Beijing,C.B.I.Press, (2004) 